\title{
Measuring of Inequality Using the Household Electricity Meter Reading Data in Urban China
}

\author{
Jihong Zhang ${ }^{\mathrm{a}}$, Chufan Luo ${ }^{\mathrm{b},{ }^{*}}$ \\ Institute of Quality Development Strategy of Wuhan University, Wuhan 430072, China. \\ aWhu_jhzhang@whu.edu.cn, ${ }^{\mathrm{b}}$ Icf622@outlook.com \\ ${ }^{*}$ Corresponding author
}

Keywords: inequality, electricity meter reading data, urban village, China

\begin{abstract}
In order to overcome the limitations of using the household survey data, the household electricity meter reading data was used to measure inequality in this study. The Gini coefficient, Lorentz curve, Theil index were used in the discussions of inequality which were carried out on the basis of distribution of year-round and monthly electricity consumption of households in village, city, and urban village. The results show that the electricity consumption Gini coefficient is 0.6171 , and this value is larger than that results calculated from survey data. The inequalities for rural and urban village household are severest and second severest, and the Gini coefficients are 0.5522 and 0.5339 , respectively. This study would probably support that energy policies focusing on low-income households especially those in village and urban village should be encouraged.
\end{abstract}

\section{Introduction}

China, as the world's second largest economy in the world since 2010, has replaced the United States as the world's leading energy consumer since 2009. Meanwhile, the income inequality in China has surpassed that in the United States and ranks first in the world [8]. The growing inequality has increased the risk of social instability and is ranked as the nation's top social challenge, above corruption and unemployment [7]. In addition, China, whose households make up approximately a quarter of the world's, is facing a rapid rural-urban transition and transformation. It is estimated that from 2010 to 2025,300 million Chinese who are currently living in rural areas would move into cities [6], while the number is almost as large as the entire population of the U.S.. Therefore, it is imperative to address efficiency of energy distribution, and to ensure equal energy consumption rights to more people, especially the low income households.

In this study, the inequality was measured on the basis of household electricity meter reading data of Guangzhou City with 100\% coverage rate of electricity. Electricity, the most widely used energy source in modern society, accounts for $21.4 \%$ of Chinese family average energy consumption and for both urban and rural households, electricity consumption expenditure is the highest in the total households' energy consumption expenditure [9] and it is one of the indicators used to measure the level of comfort and welfare of people[1]. Meanwhile, household electricity meter reading data may fully reflect the households' real economic status compared with income and consumption data due to it can circumvent the inaccurate household survey data and prevent the small sample size of high-income households. Guangzhou, which ranks the third place in China top 100 cities rankings [10] and is also regarded as one of the world-class first-tier cities [11], is an epitome of China's economic development and an example of urban development in China. With the rapid development of China and other developing countries, most developing cities will probably imitate Guangzhou's development path and accelerate urbanization. Therefore, researching on Guangzhou has significant reference meanings. What's more, unlike the existing studies that divide people into urban and rural sub-populations, three types of households were classified based on the place of residence, including "households in city", "households in village", and "households in urban village", and the contribution 
degree of households in urban village to the electricity consumption inequality was calculated for the first time. Besides, the monthly electricity consumption data was presented, which showed the dynamic changes of the electricity consumption inequality. This study seeks to objectively reflect the current situation of China's household electricity consumption inequality and provide reference for China's "fair-efficiency" type of energy policy.

\section{Data}

We randomly selected the households of Guangzhou with " 0 " at the end of the household electricity user number and got the monthly electricity consumption data from 10732 households. We excluded the abnormal household samples whose electricity consumptions were 0 for several consecutive months and obtained 8,335 valid samples, including 1,820 in village, 4,457 in city, and 2,058 in urban village ${ }^{1}$.

\section{Methods of Measuring Electricity Inequality}

Many approaches can study inequality, among which Gini coefficient (Lorentz curve) can well visualize the difference between households in consumption. Theil coefficient can identify the intra-regional gap and inter-regional differences through the decomposition of inequality, and identify the main factors causing inequality. This paper uses Gini coefficient and Theil index to measure the inequality of power consumption, aiming to make a more comprehensive analysis of China's power consumption inequality.


Fig. 1 Lorentz curve of monthly electricity consumption of households in different areas. (a). total households; (b). rural households; (c). urban households; (d). households in urban village.

\footnotetext{
${ }^{1}$ Urban villages are villages that appear on both the outskirts and the downtown segments of major Chinese cities, including Beijing, Shenzhen and Guangzhou. They are surrounded by skyscrapers, transportation infrastructures, and other modern urban constructions. Urban villages are a unique phenomenon that formed part of China's urbanization efforts. (https://www.wikipedia.org/)
} 


\section{Results and Discussion}

\section{Analysis of the Calculation Results of the Gini Coefficient (Lorentz Curve)}

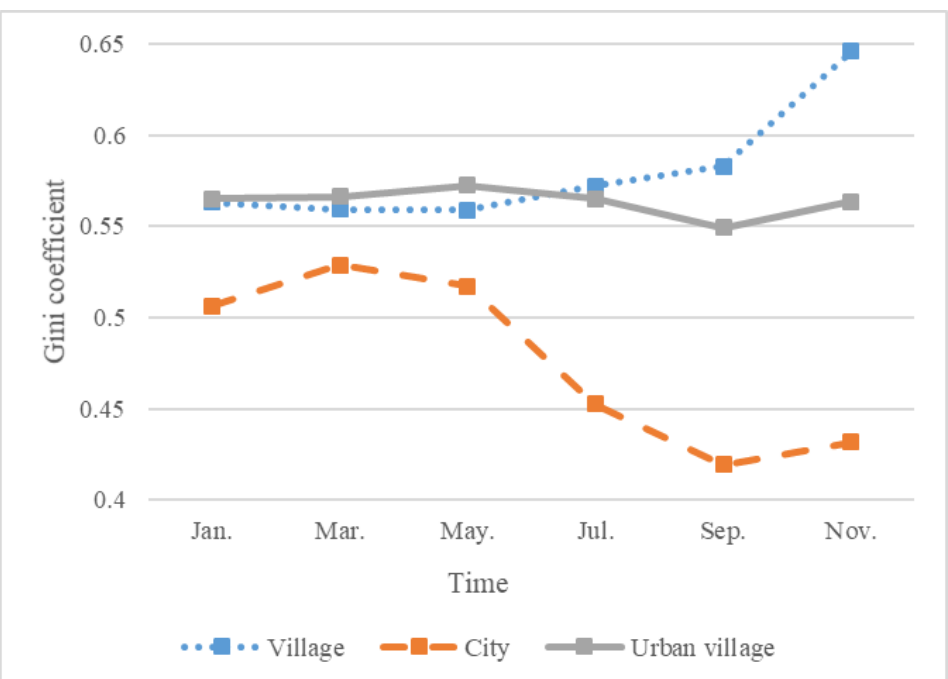

Fig. 2 Gini coefficient of monthly electricity consumption of households in village, city, and urban village.

Fig. 1 shows the Lorentz curve of monthly electricity consumption of households in village, city, and urban village. The diagonal is the line of perfect equality and the first and second numbers presented in parentheses are the Gini coefficient and Lorenz asymmetry coefficient (LCA). Fig.1 (a). shows the Lorentz curve of year-round and monthly electricity consumption of total households. The result proves that the Gini coefficient of total household electricity consumption was 0.6171 , which was significantly higher than the results calculated by other household income data, such as 0.473 from NBS (2016) and 0. 539, 0.532 from Xie \& Zhou (2014), but close to 0.603 from Gan (2017). Since electricity is the most basic consumption expenditure of a household, if the total expenditure of household consumption is considered, the Gini coefficient will increase further. Therefore, we believe that the inequality of China is likely to be underestimated, which mainly resulted from the absence of high-income household samples in survey. In addition, the Gini coefficient of household electricity consumption per month all exceeded 0.6 , and LAC was greater than 1 , indicating that the $10 \%$ households with the highest electricity consumption consumed about $40 \%$ of the total household electricity consumption, that is, the overall electricity consumption inequality of residents was mainly caused by few households with high electricity consumption. Month by month, Gini coefficients of total household electricity consumption from January ${ }^{2}$ to May were generally higher than that from July to November, among which the maximum value was 0.6759 in May and the minimum value was 0.6097 in September, which showed that the inequality of total household electricity consumption in non-summer months was higher than that in summer months.

Fig.1 (b). shows the Gini coefficient and Lorentz curve of year-round and monthly electricity consumption of households in village. The Gini coefficient of rural household year-round electricity consumption was 0.5522 , which was higher than that of urban households $(0.5339)$ and households in urban village (0.4256), indicating that the inequality of rural household electricity consumption was severest among these three types of households. At the same time, it can be seen that the year-round and monthly LAC of rural households were less than 1, indicating that the inequality of rural household electricity consumption was mainly caused by a large number of households with low electricity consumption. In addition, the trend of the Gini coefficient of rural household electricity consumption was generally contrary to that of total household (see Fig.2): the Gini coefficient increased gradually from January to November, reflecting that the Gini coefficient in summer months

\footnotetext{
${ }^{2}$ Months presented in the figures are the actual meter reading time when the electricity consumption of the first two months were recorded. E.g. the data of Mar. is the total electricity consumption of Jan. and Feb.
} 
was significantly higher than that in non-summer months. Specifically, the Gini coefficient in November was the largest (0.6458), 15.5\% higher than the minimum in May (0.5590), and 10.8\% higher than the value in September $(0.5828)$. However, the average electricity consumption in November $(401.79 \mathrm{~kW} \cdot \mathrm{h})$ was $35.4 \%$ lower than $621.85 \mathrm{~kW} \cdot \mathrm{h}$ in September, evincing that low-income rural households were very sensitive to electricity consumption expenditure and most of them chose to reduce their electricity consumption in September and October (actual meter reading time was November), which still belonged to summer whilst the temperature has decreased compared with the midsummer in July and August.

The electricity consumption of urban households was the most equally distributed, with the lowest Gini coefficient, at 0.4256 (see Fig. 1 (c).). The LAC for the whole year and most months was greater than 1, and only less than 1 in September, showing that the inequality of electricity consumption of urban households was mainly caused by a small number of high-power consumers. In September, the Gini coefficient was the lowest around the year, at 0.4192, and the LAC was 0.9673, which indicates that during July and August, the hottest months in summer, the electricity consumption inequality of urban household was mainly due to the low and middle power consumption groups in city. In addition, the trend of monthly variation of the Gini coefficient was opposite to that of rural households (see Fig.2), which indicated that the distribution of urban household electricity consumption in summer months was more equal than in non-summer months.

The Gini coefficient of year-round electricity consumption of households in urban village was 0.5339 , which basically kept unchanged and the monthly variation range was within $3 \%$. Meanwhile, the monthly Lorentz curve almost coincided with each other (see Fig. 1(d).). However, the Gini coefficient of household electricity consumption in urban village in summer was lower than that in non-summer (see Fig.2), which indicated that the distribution of household electricity consumption in urban village was fairer in summer months when electricity consumption increased significantly than that in non-summer months. The year-round and monthly LAC were approximate to 1 , which showed that the contributions of households with high and low power consumption in urban village to the inequality of power consumption were balanced, and the difference of average household power consumption might come from the difference in the number of households in each low-rent house. Besides, although the year-round and monthly LAC of households in urban village were similar to 1, LAC in May and July was greater than 1, at 1.0031 and 1.0089 respectively, while LAC in September and November was less than 1 , at 0.9606 and 0.9734 respectively. The significant reversal suggested that the main contributors of inequality in urban village rotated obviously with the seasons, and the inequality in summer was mainly caused by the low-income households.

However, the monthly changes of the Gini coefficient and the LAC of the three types of households showed a common fact that the extra costs of summer high temperature (E.g. thermoplegia) were more borne by the low-income households. With the magnifying severity of climate change and the increasing frequency of high temperature weather, this problem will undoubtedly become more serious.

What's more, it should be noted that although the calculation results showed that the electricity consumption inequality of households in village was the starkest. Considering the actual situation, the electricity consumption inequality of households in urban village might be greater. Even though the "one-house one meter" system is widely popularized in Guangzhou, due to the particularity of urban villages, a meter of one house usually contains the electricity consumption of many households. It can be seen from the statistical description above that under the same block tariff, the electricity consumption of most households in urban village reached the third level, as well as the highest level of the tariff (above $401 \mathrm{~kW} \cdot \mathrm{h}$ in winter from November to April , above $601 \mathrm{~kW} \cdot \mathrm{h}$ in summer from May to October [12]). In summer, the electricity price from the first to the second level increased by only $0.05 \mathrm{yuan} / \mathrm{kW} \cdot \mathrm{h}$, while from the second to the third level, the increase of the price was four times more than the former situation, reaching $0.25 \mathrm{yuan} / \mathrm{kW} \cdot \mathrm{h}$. For the tenants of urban village in Guangzhou, the actual cost of electricity is generally 1.5 yuan $/ \mathrm{kW} \cdot \mathrm{h}[13,14]$, while the highest level of electricity price in Guangzhou is $0.8921 \mathrm{yuan} / \mathrm{kW} \cdot \mathrm{h}$. That is to say, many tenants in urban village 
pay almost 1.7 times as much as the highest price. Therefore, if the real cost of electricity is calculated, the Gini coefficient of City Village may be larger [14].

\section{Analysis of the Calculation Results of Theil index}

Table1. Decomposition of the difference in household electricity consumption by the Theil index.

\begin{tabular}{|c|c|c|c|c|c|}
\hline Time & Village & City & $\begin{array}{l}\text { Urban } \\
\text { village }\end{array}$ & $\begin{array}{l}\text { Between } \\
\text { groups }\end{array}$ & Total \\
\hline Jan. & 0.1287 & 0.4012 & 0.1740 & 0.3237 & 1.0275 \\
\hline Mar. & 0.1238 & 0.4174 & 0.2041 & 0.2603 & 1.0055 \\
\hline May. & 0.1251 & 0.4156 & 0.1817 & 0.3388 & 1.0613 \\
\hline Jul. & 0.1347 & 0.2695 & 0.1717 & 0.2786 & 0.8544 \\
\hline Sep. & 0.1411 & 0.2052 & 0.1545 & 0.2573 & 0.7582 \\
\hline Nov. & 0.1751 & 0.2349 & 0.1619 & 0.3016 & 0.8735 \\
\hline All year & 0.1226 & 0.2614 & 0.1506 & 0.2883 & 0.8228 \\
\hline
\end{tabular}

From Table 1, we can see that the year-round Theil index of total households was 0.8228 . The total Theil index in non-summer months (January, March and May) were 1.0275, 1.0055, and 1.0613 respectively, higher than that in summer months (July, September and November): 0.8544, 0.7582, and 0.8573 . The Theil index of urban households in non-summer months all exceed 0.4, at 0.4012, 0.4174 , and 0.4156 respectively, larger than $0.2695,0.2052$, and 0.2349 in summer months. In contrast, the Theil index of rural households in summer months was larger than that in non-summer months, which increased gradually with temperature, from 0.1287 in January to 0.1751 in November. The Theil index of households in urban village fluctuated slightly with the month, the maximum value was 0.2041 in March and the minimum value was 0.1545 in September, which were basically consistent with the calculation results of Gini coefficient.

From Fig.3, we can see that the inequality can be divided into intra-group and inter-group disparity among the three types of groups (households in village, city, and urban village). The inter-group disparity contributed the most to the total inequality, reaching $35.03 \%$, followed by the disparity of households in city, contributing $31.77 \%$, then the disparity of households in urban village, contributing $18.3 \%$, and the contribution of inequality within households in village was the smallest, at $14.9 \%$, while the total contribution of inequality within the three types of households was $64.97 \%$. As far as we know, we measured the contribution of households in urban village to the inequality for the first time, different from the existing studies that only divide people into urban and rural sub-populations. The monthly fluctuation of the Theil index shows that a high temperature weather would lead to a greater disparity in electricity consumption between the urban and rural households, and the disparity between the groups contributed most to the overall inequality in summer months, accounting for $33.93 \%$ in September and $34.53 \%$ in November. Similarly, the contribution of households in both village and urban village to the overall electricity consumption inequality also reached its maximum in summer months (September and November). In contrast, that of households in city reached a maximum of $41.51 \%$ in March and dropped to $26.89 \%$ in September. 


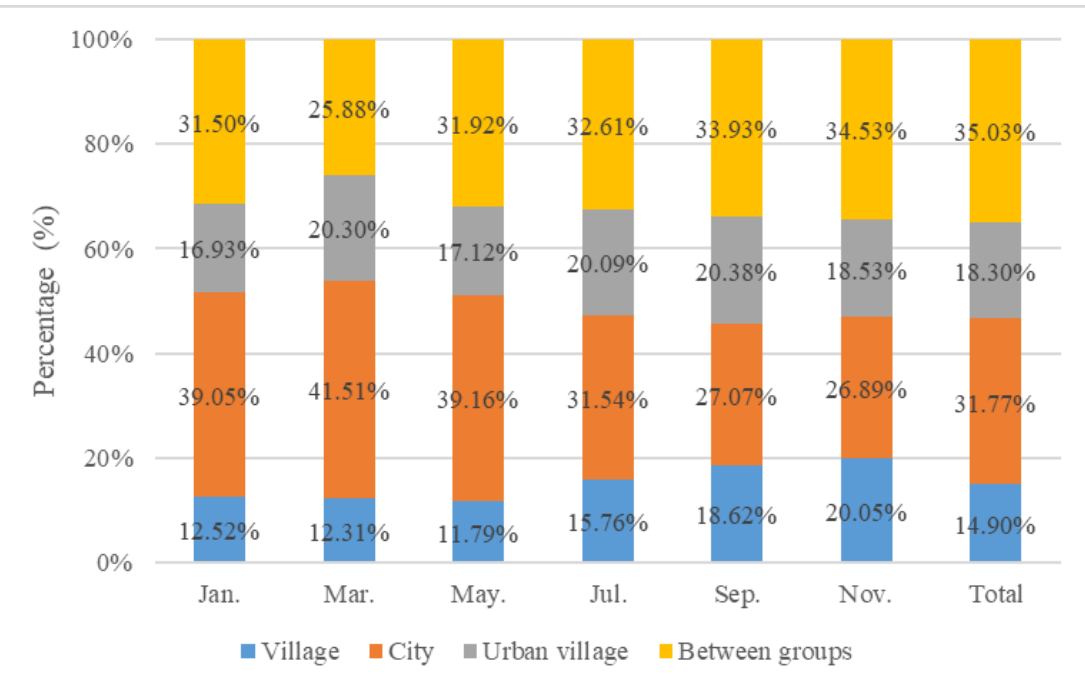

Fig. 3 Contribution rate of intra-group and inter-group (households in village, city, and urban village) electricity consumption gap to the total household electricity consumption inequality.

\section{Conclusions and Policy Implications}

Although China has achieved the goal of full coverage of household electricity during the 12th Five-Year Plan period, the electricity consumption Gini coefficient of Guangzhou which is the most developed city in China, still reaches as high as 0.6171 , exceeding the warning level 0.4 (defined by United Nations Development Program), much higher than the value in NBS (2016) (0.4650) [15], Xie $\&$ Zhou (2014) (0.5390, 0.5320), but close to the value from $\operatorname{Gan}(2017)$ (0.6040) (see Fig.4), demonstrates the fact that inconsistent with the downtrend of Gini coefficient published by NBS [16]. The inequality in China is likely to be underestimated due to lacking of high-income samples in the household survey, and the ability to pay electricity fee is an important factor hindering the fairness of the electricity consumption.

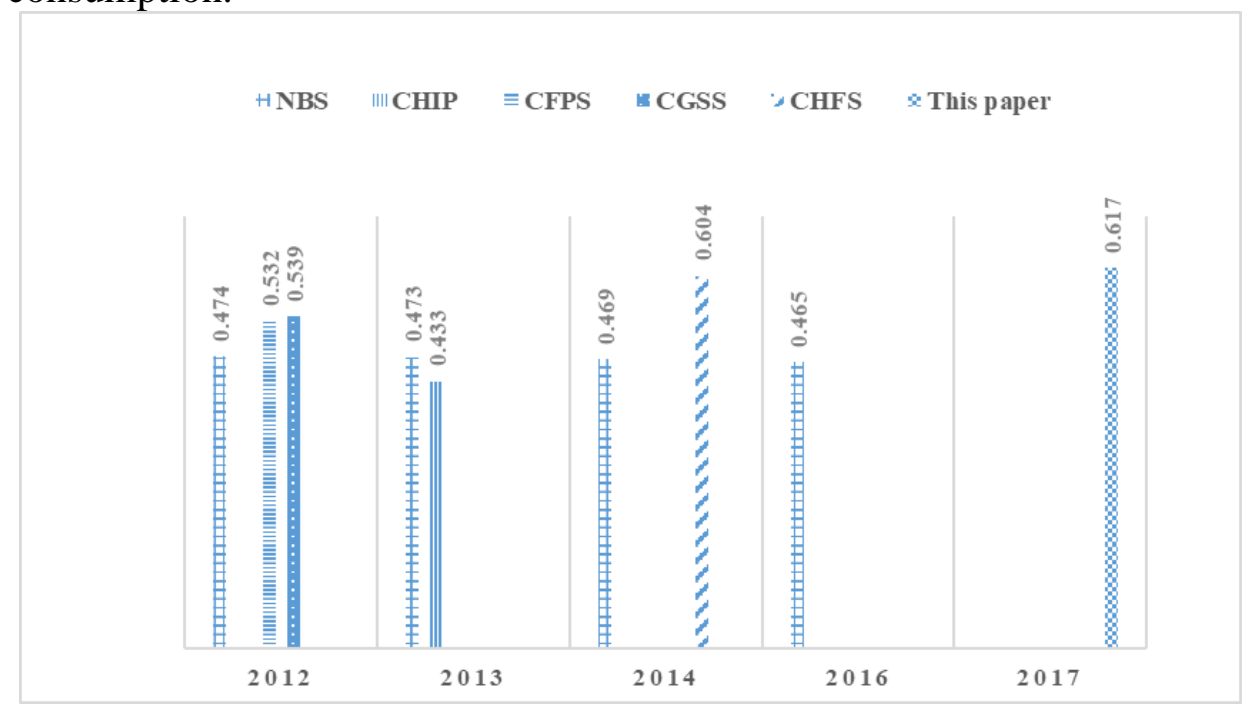

Fig. 4 Gini coefficient results calculated from different data (Note: NBS: National Bureau of Statistics of China; CHIP: Chinese Household Income Project ; CFPS: China Family Panel Studies; CGSS: Chinese General Social Survey; CHFS: China Household Finance Survey)

It is the first time that the electricity consumption inequality of households in urban village was measured and the results show that the electricity consumption Gini coefficient of households in urban village was 0.5339 , higher than 0.4256 of urban households, but lower than 0.552 of rural households. At present, China's energy policy generally ignores the basic rights and interests of households in urban village in fair energy use. By 2025, it is estimated that nearly 300 million people will migrate from rural areas to urban areas, most of whom are urban migrant workers who would 
choose to rent in urban village first. Although these households have the lowest electricity consumption, they pay 1.7 times of the highest electricity price.

Through the monthly calculation of Gini coefficient and Theil index, it can be found that the cost of high temperature in summer is more borne by low-income households. With the rapid adoption of air conditioners (that are reversible as heat pumps) in urban China over the past decade, cooling and heating have become one of the main drivers of residential electrical consumption growth [4]. The negative impact of electricity inequality is not only about the inequality of energy distribution itself, but also the secondary inequality caused by high temperature and other reasons. More electricity consumption will further exacerbate the rise of climate temperature. The low-income groups are more vulnerable and easily exposed to Thermoplegia, heat stroke, and pollution (volatilization of harmful substances) caused by high temperature. Therefore, energy policies should focus on both the price increase for the average household and the negative impact of price changes on low income households. Meanwhile, more differential price mechanisms should be implemented for different income levels [2]. For example, for the current block tariff, annual electricity measurement can be added to the basis of current monthly accounting mechanism, so that the low-income households can adjust their electricity consumption more flexibly throughout the year, and use the surplus electricity from non-summer moths in summer months, thus enjoy a lower price throughout the year. On top of that, issuing the "power vouchers" to alien workers or entitling migrant workers to apply for electricity compensation may be a helpful approach to solve the problem. Certainly, further strengthening of the power infrastructure will be a better choice. Specifically, households renting in urban village can apply for the installation of independent meters to the local power sector with subsidies. And the government should also guide high-income households to save energy through electricity price mechanism, which is conducive to the further increase of social welfare.

\section{Acknowledgment}

This work was supported by the National Key R\&D Program: Carbon Allowance Allocation Method and Capacity Building in Key Industries and Regions of China (grant number 2018YFC1509005)

\section{References}

[1] Achão C, Schaeffer R. Decomposition analysis of the variations in residential electricity consumption in Brazil for the 1980-2007 period: measuring the activity, intensity and structure effects[J]. Energy policy, 2009, 37(12): 5208-5220.

[2] Du G, Sun C, Fang Z. Evaluating the Atkinson index of household energy consumption in China[J]. Renewable and Sustainable Energy Reviews, 2015, 51: 1080-1087.

[3] Gan, L. 2017, "Income Inequality and Insufficient Consumption in China", presentation at the 6th Annual JRCPPF Conference " Escalating Risks: China's Economy, Society and Finaneial system," Princeton University, Febru-ary 16 17, 2017, http: //jre. princeton. edu/ sites/jrc/files/gan li_ac -2017. pdf.

[4] Li Y, Pizer W A, Wu L. Climate change and residential electricity consumption in the Yangtze River Delta, China[J]. Proceedings of the National Academy of Sciences, 2019, 116(2): 472-477.

[5] National Bureau of Statistics, 2016, " China's Economy Realized a Moderate but Stable. and Sound Growth in 2015, 19 January, htp: //www. stats.gov. cn/english /Press Release 201601/t201601_19._1306072. html. Accessed January 8,2017.

[6] Sun C, Ouyang X, Cai H, Luo Z, Li A. Household pathway selection of energy consumption during urbanization process in China. Energy Convers Manage 2014;84:295-304.

[7] Woellert, L. \& Chen, S. China's Income Inequality Surpasses US, Posing Risk for Xi. Bloomberg (28 March 2014). 
[8] Xie Y , Zhou X . Income inequality in today's China.[J]. Proceedings of the National Academy of Sciences of the United States of America, 2014, 111(19):6928.

[9] Information on http://news.ruc.edu.cn/archives/180329

[10] Information on http://sh.chinadaily.com.cn/2017-11/13/content 34477215.htm

[11] Information on http://inews.ifeng.com/news_51249881/sharenews.shtml

[12] Information on http://gz.bendibao.com/life/2018529/241111.shtml

[13] Information on https://www.sohu.com/a/271699026_147557

[14] Information on https://news.pchouse.com.cn/70/704592_all.html

[15] Information on http://www.stats.gov.cn/ztjc/zdtjgz/yblh/zysj/201710/t20171010_1540710.html

[16] Information on http://www.gov.cn/xinwen/2017-01/20/content_5161566.htm 